\title{
The synergy between percutaneous coronary intervention with TAXUS and cardiac surgery study: A surgical perspective
}

\section{Jacques van Wyk}

Panorama Medi-Clinic and Department of Cardiothoracic Surgery,

University of Stellenbosch, South Africa

Address for correspondence:

Dr Jacques van Wyk

Room $\mathrm{H} 04$

Panorama Medi-Clinic

Rothschild Boulevard

Panorama

7506

South Africa

Email:

jacqueswwyk@telkomsa.net

\section{INTRODUCTION}

The treatment of symptomatic coronary artery disease has undergone major developmental changes in the last few decades. Coronary artery bypass surgery has become a safe procedure with in-hospital mortality that averages $1 \%$ in low risk patients and between 2-5\% in all risk patient groups. New innovations like less invasive techniques (mini-bypass, off-pump surgery), arterial revascularisation, optimal cardio-protective measures, major advances in anaesthetic technique and improved perioperative care has improved outcomes after coronary bypass surgery. ${ }^{(9,15,16)}$

Since the inception of $\mathrm{PCl}$ in 1977 by Gruentzig, the treatment of stenotic coronary artery disease has changed forever. The introduction of bare metal stents (BMS), then drug-eluting stents (DES) and new anti-platelet therapy has been the stimulus to treat more complex coronary artery lesions with percutaneous techniques.

Several studies of multi-vessel coronary disease have shown relative comparative mortality rates in both treatment groups, with only higher repeat revascularisation rates in the $\mathrm{PCl}$ groups. When reflecting on these results the question arises if CABG is still the

\section{ABSTRACT}

The SYNTAX (The Synergy between percutaneous coronary intervention with TAXUS and cardiac surgery) study is an important study to indicate the best treatment option for patients who have three vessel coronary artery disease and/ or left main stem coronary disease (LMD). CABG (coronary artery bypass grafting) is still the preferred therapy for these patient groups with proven low mortality and excellent long term survival rates. PCI-DES (percutaneous coronary intervention with drug eluting stents) is a relative non-invasive procedure with comparable short and medium term survival, but with a much higher repeat revascularisation rate.

The SYNTAX Study enrolled 1800 patients in a randomised arm and 1275 in a registry arm. A SYNTAX Score was developed to assess the lesion morphology. At 12 months follow-up in the randomised group there was an increased death rate $(4.3 \%$ vs $3.5 \%)$, myocardial infarction rate $(4.8 \%$ vs $3.2 \%)$ and repeat revascularisation rate $(13.7 \%$ vs $5.9 \%)$ in the PCI-TAXUS (percutaneous coronary intervention with TAXUS stent) group compared to the CABG group. This trend continues up to $\mathbf{2 4}$ months with increased death rate (6.2\% vs $4.9 \%)$, myocardial infarction rate $(5.9 \%$ vs $3.3 \%)$, repeat procedure rate $(17.4 \%$ vs $8.6 \%)$ and MACCE rate (23.4\% vs $16.3 \%$ ) in the $\mathrm{PCl}$ group compared to the CABG group.

The aim of the SYNTAX Study was to prove non-inferiority of $\mathrm{PCl}$ (percutaneous coronary intervention) compared to CABG in these patient populations. Non-inferiority of $\mathrm{PCl}$ TAXUS compared to CABG in this study population could not be shown at 12 or 24 months.

The cerebrovascular event rate was higher in the CABG group in both study arms $(2.2 \%$ vs $0.6 \%)$ in the first year, but a nearly similar CVA rate during the next 12 months.

The study will terminate in $201 \mathrm{I}$ and will give much-needed information regarding the optimal treatment option in patients with three vessel disease and/or left main disease. SAHeart 2009; 6:230-235

gold standard for left main (LM) and three vessel coronary artery disease.

The SYNTAX (Synergy between percutaneous coronary intervention with TAXUS and cardiac surgery) Study was designed to show that $\mathrm{PCl}-\mathrm{DES}$ is not inferior to $\mathrm{CABG}$ in randomised patients 
with three vessel disease and/or LMD. The SYNTAX Study is the most important comparative evidence-based study to determine the best treatment option for LM and three vessel disease.

\section{CURRENT EVIDENCE FOR TREATMENT IN MULTI-VESSEL CORONARY ARTERY DISEASE}

Multiple randomised control trials comparing $\mathrm{PCl}$ and $\mathrm{CABG}$ in the last \pm 20 years have failed to address the issue of LM and three vessel disease. Fifteen RCT including RITA, ERACI I, GABI, EAST, CABRI, MASS I, BARI, AWESOME, MASS II, ARTS I and SOS trials gave inconclusive results regarding this aspect. (1-8) $^{(-1)}$

In summary all of these studies included only $35 \%$ of three vessel disease, $0 \%$ had LM disease, only 43\% had proximal LAD (left anterior descending artery) disease, 100\% had ejection fractions of $>50 \%$, diabetes was only present in 16\%. The studies exclude the bulk of patients that would benefit from CABG (Table I).

In the studies where BMS (bare metal stenting) was used, namely ERACI II, ARTS I, SOS and AWESOME the rate of repeat revascularisation was reduced significantly, but was still high. In the SOS and ARTS I trial (67\% - 72\% 2VD; 0\% LM) the repeat revascularisation was 30\% (BMS) vs $9 \%$ (CABG) in the ARTS I trial and $21 \%$ (BMS) vs $6 \%$ (CABG) in the SOS trial. The combined MACCE (death, MI, stroke, repeat revascularisation) was $41.7 \%$ in the BMS group and $21.8 \%$ in the CABG group. In the 5 year follow-up in the MASS ॥ trial comparing CABG, PCl (BMS) and medical treatment groups, there was a 10 time higher incidence of repeat interventions in the $\mathrm{PCl}$ group in comparison with the CABG group (32.2\% vs 3.5\%). There was also a mild mortality difference over the 5 years favouring CABG (I5.5\% (PCl) VS $12.8 \%$ (CABG)). These studies tended to give a biased view with only a low percentage (4\%) of screened patients being randomised. The trials excluded patients that would benefit from bypass surgery i.e. those with three vessel disease, left main disease, patients with diabetes mellitus and those with impaired left ventricle function $(<50 \%)$. Although these studies were not representative of daily clinical practice, the results were generalised. ${ }^{(19)}$ A search for "real world" evidence in registries developed from these highly selective patient trials. Hannan et al. published the 3 year outcome of coronary artery bypass grafting vs stent

TABLE I: Summary of 15 randomised control trials comparing PCI vs CABG in multivessel disease

\begin{tabular}{|c|c|c|c|c|c|c|c|c|}
\hline Trial & $\begin{array}{l}\text { No of } \\
\text { patients }\end{array}$ & Stent & $\%$ Left main & $\% 3 \mathrm{VD}$ & Proximal & $\begin{array}{l}\text { EF }>50 \% \\
\operatorname{LAD}(\%)\end{array}$ & $\%$ DM & $\%$ IMA \\
\hline RITA & 1011 & - & 0 & 12 & - & - & 6 & 74 \\
\hline ERACl & 127 & - & 0 & 45 & - & 100 & 11 & 75 \\
\hline LAUSANNE & 134 & - & 0 & 0 & 100 & - & 12 & 100 \\
\hline GABI & 359 & - & 0 & 18 & - & - & 10 & 37 \\
\hline EAST & 392 & - & 0 & 40 & 70 & 100 & 25 & - \\
\hline CABRI & I 054 & - & 0 & 40 & - & 100 & 12 & 75 \\
\hline MASS & 142 & - & 0 & - & 100 & 100 & 21 & 100 \\
\hline BARI & 1829 & - & 0 & 41 & 36 & 100 & 24 & 80 \\
\hline TOULOSE & 152 & - & 0 & 29 & - & - & 14 & 58 \\
\hline SIMA & 121 & - & 0 & - & 100 & 100 & 11 & 100 \\
\hline ERACI II & 450 & + & 0 & 56 & - & - & 17 & 88 \\
\hline AWESOME & 454 & + & 0 & 45 & - & - & - & 70 \\
\hline MASS II & 408 & + & 0 & 41 & 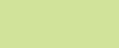 & & & \\
\hline ARTS & | 205 & + & 0 & 32 & - & 100 & 19 & 93 \\
\hline sos & 988 & + & 0 & 38 & 45 & 100 & 14 & 81 \\
\hline Summary & 8826 & & 0 & 35 & 41 & 100 & 16 & 79 \\
\hline
\end{tabular}

A summary of the randomised trials comparing PCl and CABG. It shows the trial, the number of patients included in the trial, stents was implanted in only the last 5 trials. The next column shows the \% of LMD included in each trial. The amount of patients with three vessel disease was low in the PCI group. The LV function was good in all of these patients.

Use with permission from Prof DP Taggart: Presented at the Fall 2006 Annual Meeting of the Southern Thoracic Surgical Association (STSA). Thomas B. Ferguson Lecture. 
implantation in the New England Journal of Medicine of 26 May 2005. The New York State Cardiac Surgery and Coronary Percutaneous Intervention database was used. Thirty seven thousand two hundred and twelve (37 212) patients with multivessel disease underwent CABG and 22102 patients underwent stenting between I January 1997 and 31 December 2000. Primary outcomes investigated were death and repeat revascularisation. In the $C A B G$ group $0.3 \%$ underwent re-CABG and $4.6 \%$ underwent $\mathrm{PCl}$ in the 3 year time period. In the $\mathrm{PCl}$ group $7.8 \%$ underwent $\mathrm{CABG}$ and $27.3 \%$ underwent repeated $\mathrm{PCl}$. The observed rate of revascularisation in the $C A B G$ group was significantly lower $(p<0,001)$.

When comparing the $\mathrm{PCl}$ and $C A B G$ group there was a survival benefit for $C A B G$ over the 3 years. There was a significant survival benefit in the group of patients who had three vessel disease and involvement of the proximal LAD ( $89.3 \%$ vs $84.4 \%$ survival when comparing CABG vs $\mathrm{PCl}$ over these 3 years). ${ }^{(9)}$

This was an observational study and not a randomised control study and was therefore criticised by Flaherty. He concluded that there are major flaws in the study and he emphasised that there was a risk-ascertainment bias between the two groups and therefore the difference in adjusted outcome in this study. ${ }^{(17)}$

Very few of these patients received drug-eluting stents (DES). Hannan et al reviewed the same databases in New York State to evaluate the influence of DES and CABG on major adverse outcomes (death, myocardial infarction) or repeat revascularisation in a patient population from I October 2003 to 3 I December 2004. Those patients with previous revascularisation, main stem disease and those with recent myocardial infarctions were excluded. The study population included 9963 DES patients and 7437 CABG patients. The outcomes up to 18 months after the initial procedure were reviewed.

It was a purely observational, non-randomised, retrospective study of a "real world" situation. The revascularisation rate in the $C A B G$ group was low with $0,1 \%$ of patients requiring repeat $C A B G$ and $5.1 \%$ in the $\mathrm{PCl}$ group receiving repeat procedures. In the DES group $2.2 \%$ required $C A B G$ and $28.4 \%$ required repeat $P C I$.

In the three vessel and two vessel disease subgroup there was an adjusted long term survival benefit in the CABG group ( $92.1 \%$ vs $89.7 \%$ (DES); $p<0,001$ ). Comparing subgroups of patients with diabetes, left ventricle ejection fraction $<40 \%$ and patient age $>80$ years the conclusion was made that there was no mortality difference between the two groups but the rate of death or myocardial infarction was lower in the poor left ventricle function patients and in the patients $>80$ years that was treated with CABG. ${ }^{(10)}$

\section{THE SYNTAX STUDY}

(The synergy between percutaneous coronary intervention with TAXUS and cardiac surgery).

The SYNTAX Study is a phase III multi-centre, international, randomised controlled comparison of bypass surgery and $\mathrm{PCl}$ with a TAXUS drug eluting stent in 1800 patients. Included were patients with three vessel disease and/or left main stem coronary artery disease. Excluded from the study were patients with acute myocardial infarction, previous coronary intervention and those who required concomitant cardiac surgery.

\section{The study design}

Eighty five centres (62 in Europe and 23 in the USA) enrolled patients for the trial. One thousand eight hundred (I 800) patients were randomly assigned by a team of a local cardiac surgeon and an interventional cardiologist to undergo $C A B G$ or $\mathrm{PCl}$ with TAXUS stents in a $1: 1$ ratio. Patients were randomised only after both agreed that the patient can be treated by either intervention (CABG or $\mathrm{PCl})$.

A non-inferiority comparison of the 2 groups was performed for the primary endpoints - a major cardiac or cerebrovascular event (death from any cause, stroke, myocardial infarction or repeat revascularisation). Patients who did not qualify were entered into a separate parallel CABG or $\mathrm{PCl}$ registry.

All the angiograms were reviewed by an independent group of specialists in Rotterdam, Netherlands. A SYNTAX Score was calculated for these angiograms.

\section{SYNTAX Score}

The SYNTAX Score is an anatomical assessment score of an individual angiogram (Figure I). It is an evaluation of coronary lesion complexity and a score is assigned to it. It includes multiple factors, eg. lesion calcification, bi-or trifurcation lesions, left main or threevessel disease, thrombus, tortuosity, number and location of lesions. Scores are computer generated (www.syntaxscore.com). ${ }^{(13)}$
A score of $\leq 22$ :
Low Syntax Score
A score of 23-32: Intermediate Score
A score of $\geq 33$ : High Score 
A scoring algorhythm has been developed that addresses the following twelve aspects: Coronary artery dominance; number of lesions; segments involved per lesion; total occlusion; trifurcation or bifurcation lesions; aorta-ostial lesions; severe tortuosity; lesion length $>20 \mathrm{~mm}$; heavy calcification; thrombus; and diffuse disease/ small vessels. It is a self-guided questionnaire and a score is assigned to the information given.

One thousand eight hundred ( 1 800) patients were recruited for the study in the randomised arm: 897 in the CABG group and 903 in the TAXUS group ( $\pm 28.5 \%$ D.M.). One thousand two hundred and seventy-five ( I 275) patients were included in the registry arm $(\mathrm{CABG}=\mid$ 077, $\mathrm{PCl}=$ 198).

The primary clinical endpoint is the 1 and 2 year follow-up of major adverse cardiac and cerebral events (MACCE). The 24 month follow-up has just been completed. MACCE is defined as the all-cause death, myocardial infarction, any repeat revascularisation and cerebrovascular events. The study is ongoing and the study will terminate when 5 year follow-up has been completed.

A non-inferiority comparison between the two therapeutic entities was done. A zone of non-inferiority was specified between the differences of the MACCE rate of CABG vs PCl. The pre-specified value was $6.6 \%$. A value of less than $6.6 \%$ would suggest noninferiority for $\mathrm{PCl}$ compared to $\mathrm{CABG}$.

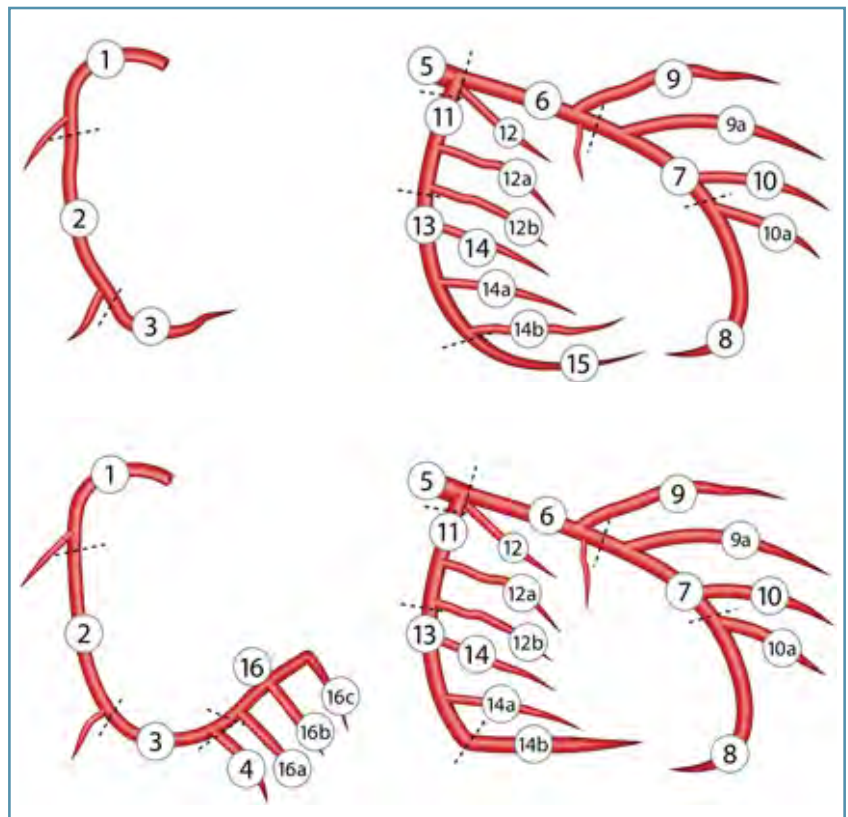

FIGURE I: Morphology of coronary artery segments for description in the SYNTAX Score (www.syntax.net)

\section{Randomised cohort of the SYNTAX Study}

Demographics between the CABG and TAXUS groups were nearly similar. Twenty eight \% of patients were diabetic and the Euroscore and Parsonnet scores were 3.8 and 8.4 respectively in both groups.

SYNTAX Score in the CABG group was 29.1 and 28.4 in the TAXUS group. Subgroups of left main (LM) disease and three vessel disease were identical in both groups (65\% and 34\%). In the TAXUS group a mean of 3.6 lesions was treated and 4.6 stents was implanted/patient. Total length of stents implanted was $86.1 \pm 47.9 \mathrm{~mm}$ and in $33.2 \%$ of patients stenting of $>100 \mathrm{~mm}$ was performed.

In the CABG group 15\% of patients were off-pump cases, $97.3 \%$ received at least one arterial graft, 95.6\% received an arterial graft to $L A D, 27.6 \%$ received double arterial grafts (RIMA/LIMA). Only $2.6 \%$ of patients received only venous grafts (Table 2 ).

\section{Primary endpoint for 12 month MACCE (The non-inferiority analysis):}

Difference in MACCE $=8.3 \%$, therefore the non-inferiority comparison was not met for the primary outcome at 12 months. ${ }^{(1)}$

\section{Subgroup MACCE rate:}

Non-inferiority was not proven in this randomised cohort, therefore information for each subgroup is of an observational nature and is hypothesis generating.

At 12 months there was an equivocal MACCE rate in the isolated left main group. In the LM+one vessel disease group there was an increase MACCE rate for CABG (13.2\%) vs $7.5 \%$ for TAXUS. For $L M+$ two vessel disease and $L M+$ three vessel disease there was a preference for CABG. $\mathrm{LM}+$ two vessel disease: $\mathrm{CABG}=$ 14.4\%, TAXUS=19.8\%; LM+three vessel disease: $C A B G=15.4 \%$, TAXUS $=19.3 \%$. For three vessel disease there was a better MACCE for CABG (11.5\% vs 19.2\% for TAXUS). In the diabetes group the MACCE rate was substantially higher in the TAXUS group than in the $C A B G$ group $(C A B G=\mid 4.2 \%$, TAXUS $=26.0 \%)$.

At 24 months the MACCE rate in the three vessel disease subgroup was $23.8 \%$ in the PCl group and $14.4 \%$ in the CABG group $(p<0.00 \mathrm{I})$. In the left main subgroup the MACCE rate was $22.9 \%$ in the $\mathrm{PCl}$ group and $19.3 \%$ in the CABG group $(p=0.27)$. 


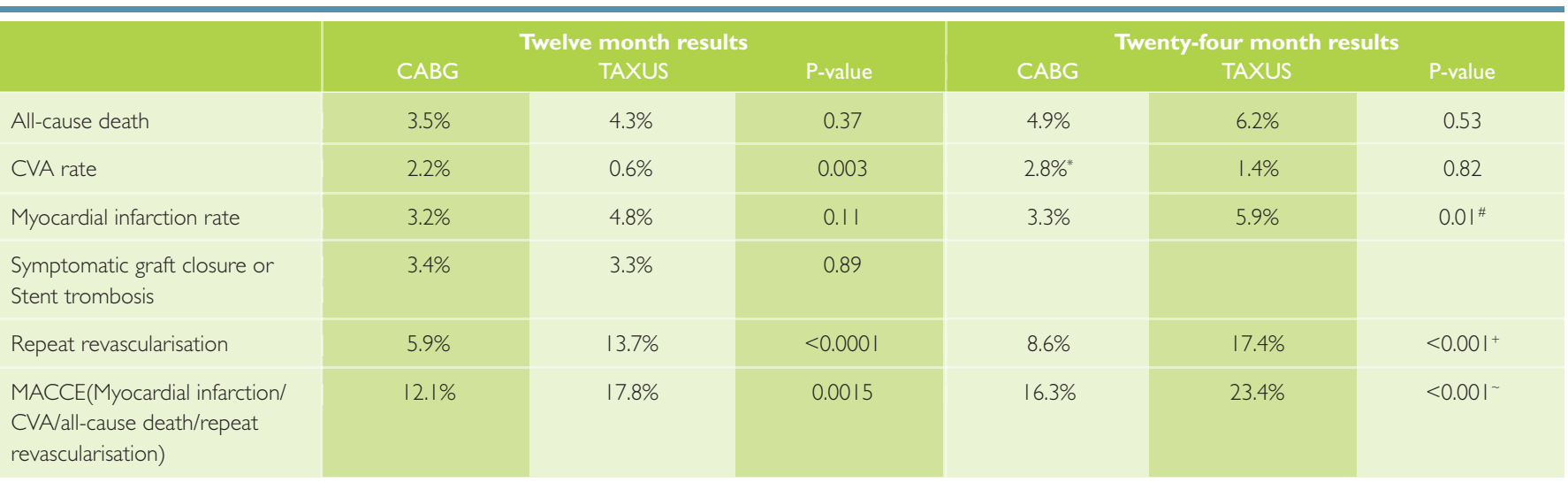

"After I year the increase in CVA for CABG was $0.7 \%$ and $0.6 \%$ for TAXUS. \#After I year myocardial infarction rate increased by $1.2 \%$ for TAXUS $0.1 \%$ for CABG(0.008).

${ }^{+}$After I year the increase of repeat revascularisation was 3.7\% for CABG and 5.6\% for TAXUS ( $p=0.06$ ). $\sim A f t e r$ I year the increase in MACCE was $5.7 \%$ for CABG and $8.3 \%$ for TAXUS ( $p=0.03$ ).

\section{RESULTS INTHE PCI AND CABG REGISTRIES}

One hundred and ninety-eight (198) patients were enrolled in the $\mathrm{PCl}$ registry and $\mathrm{I} 077$ in the CABG registry. The CABG group had a higher SYNTAX Score than the PCl group and was therefore ineligible for $\mathrm{PCl}$. The $\mathrm{PCl}$ group had a higher Euroscore, because of more co-morbidities (Table 3). ${ }^{(12)}$

\section{DISCUSSION}

The SYNTAX Study is a landmark study in the treatment of three vessel and left mainstem coronary artery disease. The allcomer design will make it possible to evaluate the proper treatment option for any given clinical situation. However it should be noted that I 077 (35\%) of all the patients screened $(n=3$ 075) were not eligible for $\mathrm{PCl}$. One hundred and ninety-eight (6.4\%) patients were not suitable for $C A B G$, due to a high logistic Euroscore.

TABLE 3: Results for the $\mathrm{PCl}$ and $\mathrm{CABG}$ registries

\begin{tabular}{|l|l|l|l|}
\hline & $\begin{array}{c}\text { Twelve month } \\
\text { results }\end{array}$ & $\begin{array}{c}\text { Twenty-four } \\
\text { month results }\end{array}$ \\
\hline $\begin{array}{l}\text { CABG } \\
\text { All-cause death }\end{array}$ & TAXUS & CABG & TAXUS \\
\hline $\begin{array}{l}\text { Cerebrovascular } \\
\text { accidents(CVA) }\end{array}$ & $2.5 \%$ & $7.3 \%$ & \\
\hline $\begin{array}{l}\text { Death / CVA / } \\
\text { Myocardial infarction }\end{array}$ & $2.2 \%$ & $0 \%$ & \\
\hline $\begin{array}{l}\text { Repeat re-vascularisation } \\
\text { Myocardial infarction }\end{array}$ & $3.0 \%$ & $12 \%$ & \\
\hline Total MACCE & $2.5 \%$ & $4.2 \%$ & \\
\hline
\end{tabular}

The higher MACCE for $\mathrm{PCl}$ in the randomised control cohort and registry was due to higher repeat procedures as well as higher myocardial infarction rates. There was also a high incidence of staged procedures in the PCI group (14.1\% in TAXUS RCT and 13.0\% $\mathrm{PCl}$ registry). The economic implications will be significant. The myocardial infarction rate continues to rise in the $\mathrm{PCl}$ group but stayed static in the CABG group $(5.9 \%$ in $\mathrm{PCl}$ group compared to $3.3 \%$ in the CABG group). This increase of myocardial infarction in the $\mathrm{PCl}$ group is most probably due to stent trombosis as well as coronary territories not completely revascularised by $\mathrm{PCl}$.

Symptomatic graft closure/stent thrombosis in RCT was similar in the two groups at 12 months. ( $C A B G=3.4 \%$ vs TAXUS $=3.3 \%$ ). Stent thrombosis is associated with a higher incidence of malignant sequelae if compared to graft closure: the reported incidence of acute myocardial infarction is $65-70 \%$ and the mortality is $25-$ 45\% post stent thrombosis. (JAMA 2005, 293: 2126-2130. Ann Int Med 2006; 144: 913 - 919; Circulation 2007; 15: 1440 - 5). The peri-procedure rate of myocardial infarction after CABG is

\section{TABLE 4: MACCE rates with reference to the SYNTAX score at} 24 months

\begin{tabular}{l|c|c|c|}
\hline & TAXUS & CABG & \\
\hline $\begin{array}{l}\text { Low SYNTAX } \\
\text { score (0-22) }\end{array}$ & $19.4 \%$ & $17.4 \%$ & $\mathrm{P}=0.63$ \\
$\begin{array}{l}\text { Intermediate SYNTAX } \\
\text { score (23-32) }\end{array}$ & $22.8 \%$ & $16.4 \%$ & $\mathrm{P}=0.06$ \\
\hline $\begin{array}{l}\text { High SYNTAX } \\
\text { score }(>32)\end{array}$ & $28.2 \%$ & $15.4 \%$ & $\mathrm{P}=0.001$ \\
\hline
\end{tabular}


3-6\%. In patients with angiographic defined post-procedure graft closure and acute myocardial infarction the mortality is $9.3 \%$ if treated with $\mathrm{PCl}$ and $39 \%$ if treated with re-CABG. ${ }^{(18)}$

A significant difference in mortality and repeat procedure in especially the three vessel disease/LM+two vessel disease/ $L M+$ three vessel disease groups favouring CABG. The reason for this increase in cardiac-related deaths in the $\mathrm{PCl}$ group is most probably due to the fact that CABG led to more complete revascularisation compared to $\mathrm{PCl}$. This is more pronounced in the registry co-hort ( $C A B G=2.5 \%, T A X \cup S=7.3 \%)$.

An increased cerebrovascular event rate in the CABG group of 1.6\%. That amounts to a 3 times higher CVA rate in the CABG group. The CVA rate during the second 12 months shows an equivocal increase in both goups.

The SYNTAX score will be an important scoring system to decide on the best treatment option. In the CABG group the MACCE rate in all the SYNTAX Score levels was similar. (0 -22: 14.7\%; 23 -32: 12\%; 233: 10.9\%), but MACCE events increased in the PCI group as the SYNTAX Score increased (0 - 22\%: I3.6\%; 23-32: 16.9\%; $\geq 33: 23.4 \%)$. This is amplified in the second year with a significant increase in MACCE in the high SYNTAX Score $\mathrm{PCl}$ group. Therefore the higher the SYNTAX Score the higher the cardiac-related complications in the $\mathrm{PCl}$ treated group.

SYNTAX will therefore identify the best treatment option for the specific coronary pathology (SYNTAX Score).

Collaboration between surgeon and interventional cardiologist will be important in the future to optimise the best treatment option. Complexity of coronary artery anatomy, the patient's risk for a specific procedure (Euroscore, Parsonnet) and the economic implications should be considered before embarking on a specific procedure. ${ }^{(14)}$

The 5 year follow-up will be completed in $201 \mathrm{I}$ and will give us much-needed information about the ideal therapy for a specific coronary artery profile.

The treatment of complex coronary artery disease should ideally be managed by a team approach. The SYNTAX Study emphasises the benefits of surgery in this patient population at two year follow up. CABG is known to have good long term results and we need to determine if the same results can be achieved by stenting. At present $C A B G$ remains the preferred treatment for complex coronary artery disease based on the two year follow up data from the SYNTAX Trial.

\section{SPECIALACKNOWLEDGEMENT}

Special thanks to Dr De Wet Lubbe for his comments and advice with the writing of this article.

\section{REFERENCES}

I. Hamm CW, Reimers J, et al. German angioplasty bypass surgery investigation (GABI). N Eng J Med. 1994;331; 1037-43.

2. RITA Trial Participants. Coronary angioplasty versus coronary artery bypass surgery: the Randomised Intervention Treatment of Angina (RITA) Trial. Lancet. 1993;341:573-580.

3. MASS-II trial Hueb W, Soares PR, Gersh BJ, et al. The medicine, angioplasty, or surgery study (MASS-II): a randomised, controlled clinical trial of three therapeutic strategies for multi-vessel coronary artery disease: one-year results. J Am Coll Cardiol 2004:43(10): 1743-1751.

4. Comparison of coronary bypass surgery with angioplasty in patients with multivessel coronary disease (BARI). N Eng J Med. 1996;335:2 17-25.

5. Hueb W, Soares PR. The medicine, angioplasty or surgery study (MASS II). J Am Coll Cardiol. 2004; 43: 1743-5।.

6. Morrison DA, Sethi G, Sacks J,et al. AWESOME trial. J Am Coll Cardiol. 2001;38: 143-9.

7. The SoS Investigators coronary artery bypass surgery versus percutaneous coronary intervention with stent implantation in patients with multi-vessel coronary artery disease (The Stent or Surgery Trial): a randomised controlled trial. Lancet 2002;360:965-969.

8. Rodriguez A, Bernardi V, Navia J, et al., for the ERACI II Investigators Argentine randomised study. Coronary angioplasty with stenting versus coronary bypass surgery in patients with multiple-vessel disease (ERACI I): 30-day and I-year follow-up results. J Am Coll Cardiol 200 I;37:5 I-58

9. Hannan E, Racz M, et al. Long-term outcomes of coronary-artery bypass grafting vs stent implantation. N Eng J Med. 2005;352:2174-83.

10. Hannan E, Wu C. Drug-eluding stents vs coronary-artery bypass grafting in multi-vessel coronary disease. N Eng J Med. 2008;358:33I-4I.

11. Serruys P, Mohr F. SYNTAX: Primary endpoint results at one year in the randomised cohort. European Society of Cardiology congress, Munich, 2008.

12. Mohr F, Serruys P. SYNTAX: One year results of the $P C l$ and $C A B G$ registries. European Society of Cardiology congress, Munich, 2008.

13. Sianos G, Morel M, Serruys P, et al.The Syntax Score: An angiographic tool grading the complexity of coronary artery disease. Eurolnterv. 2005;1:219-227.

14. Serruys P, Morice M, Mohr F. Percutaneous coronary intervention versus coronary artery bypass grafting for severe coronary artery disease. N Eng J Med.2009; 360: 961-972.

15. Petersen ED, Coombs LP. Procedure volume as a marker of quality for CABG surgery. JAMA. 2004;291:195-201.

16. Birkmeyer JD, Siewers AE. Hospital volume and surgical mortality in the United States. N Eng J Med. 2002;346: I | 28- I I 38.

17. Flaherty (Correspondence). Coronary artery bypass grafting vs stent implantation. N Eng J Med.2005;353:735-7.

18. Fabricius AM, GerberW. Early angiographic control of peri-operative ischaemia after coronary artery bypass grafting. Eur J Cardiothorac Surg.200 I Jun; I9(6):853-8.

19. Mercado, Serruys. Meta-analysis of CABG vs PCl for multi-system disease. Journal of Thoracic and Cardiovascular surgery. 2005; 130: 512-9. 